\title{
A rare association between Edward syndrome and unilateral intranasal congenital dacryocystocele with respiratory distress in a newborn
}

\author{
Ahmad Al Kurdi ${ }^{1}$, Abdullah Noman ${ }^{1}$, Kamal Atawi $^{2}$, Mohammed Abdullah ${ }^{3}$ and Khalil Altawil ${ }^{4}$ \\ ${ }^{1}$ Department of Otolaryngology, Prince Mohammed bin Abdul-Aziz hospital, Almadinah, KSA \\ ${ }^{2}$ Department of Radiology, Prince Mohammed bin Abdul-Aziz hospital, Almadinah, KSA \\ ${ }^{3}$ Department of Ophthalmology, Prince Mohammed bin Abdul-Aziz hospital, Almadinah, KSA \\ ${ }^{4}$ Department of Pediatric, Prince Mohammed bin Abdul-Aziz hospital, Almadinah, KSA
}

\begin{abstract}
Congenital dacryocystocele occurs as a result of a functional obstruction of the Rosen-Müller valve and lower anatomical obstruction of the valve of Hasner, and it is presented as a swelling at the area of medial canthus most of the times. Intra-nasal presentation of congenital dacryocystocele is not common and a few cases were reported in the literature. Edward syndrome (also known as trisomy 18) is the second -most common trisomy, which includes a multiple congenital anomalies with a poor prognosis. We are presenting a case of large unilateral intranasal dacryocystocele in a preterm male baby, who was diagnosed later as an Edward syndrome, and has had a severe respiratory distress after birth which leaded to intubation of the newborn and mechanical ventilation. Radiological evaluation by CT and MRI with diagnostic nasal endoscopy was the work-up for confirmation of the diagnosis. The patient was successfully managed by endoscopic marsupialization of the dacryocystocele cyst with a blunt probing of the nasolacrimal duct. On the second day after operation, the baby was extubated and symptoms of respiratory distressed disappeared.
\end{abstract}

\section{Introduction}

In newborns, the canalization of the lacrimal ducts is often not fully developed, about three-quarters of all newborns have a persisting Hasner's membrane at the opening of the nasolacrimal duct into the lower nasal meatus. However, despite the frequency, only $5 \%$ of the cases develop clinical symptoms like mucopurulent discharge and epiphora that often regress spontaneously in the first few months. Rarely an additional proximal stenosis at the Rosen-Müller valve at the junction of the lacrimal canaliculi and lacrimal sac may lead to a progressing accumulation of the lacrimal fluid in the lacrimal duct. This proximal narrowness works like a valve that impedes the reflux of the lacrimal fluid to proximal and allows the passage of the lacrimal fluid only in one direction [1]. The obstruction of the drain and the secretory accumulation provoke a cystic enlargement of the lacrimal duct by intracanalicular increase of pressure and lead to the formation of a dacryocystocele [2]. Congenital dacryocystocele may protrude into the nasal lumen passing the still soft bony limitation of the lacrimal duct and may lead to a nasal obstruction. Due to the fact that infants are obligate nasal breathers within the first few weeks of life this may cause respiratory distress [1]. In newborns who suffer from nasal obstruction, congenital dacryocystocele must be considered in the differential diagnosis [1].

Edwards's syndrome which is the second-most common autosomal trisomy after Down Syndrome [3] occurs in around one in 6,000 live births, and around $80 \%$ of those affected are females [4]. The majority of fetuses with this syndrome die before birth. The syndrome has a very low rate of survival, resulting from heart abnormalities, kidney malformations, and other internal organ disorders. Half of the infants with this syndrome do not survive beyond the first week of life [5]. About $8 \%$ of infants survive longer than 1 year [6]. One percent of children live to the age of ten, typically, in less severe cases of the mosaic Edwards syndrome [7].

\section{Case report}

A preterm baby male 36 week of gestational age, product of an emergency caesarean section of a mother 45 year old with polyhydramnios, and no other medical problems. Apgar score was 6 at $1^{\text {st }}$ minute and 8 at $5^{\text {th }}$ minutes, the baby developed a respiratory distress shortly after birth with desaturation. Suspicion of bilateral choanal atresia was

raised by the neonatology team due to the failure of introducing soft catheters in both nostrils. The baby was intubated and put on mechanical ventilation in NICU. The baby had a dysmorphic features on clinical examination: slanted and narrow palpebral fissure, epicanthus, abnormal long lashes, blepharophimosis, anisocoria, micrognathia, small face, upturned nose, malformed low set ears, clenched hand with overlapping fingers (index finger over third finger and fifth finger over fourth finger), imperforated anus, right undescended testes with

Correspondence to: Abdullah Noman, Department of Otolaryngology, Prince Mohammed bin Abdul-Aziz hospital, Almadinah, KSA, Tel: 00966531423929; E-mail: NomanAb1@NGHA.MED.SA

Key words: newborn, dacryocystocele, respiratory distress

Received: October 10, 2017; Accepted: October 28, 2017; Published: October 31,2017 
hypospadias, right inguinal hernia (Figure 1). Echocardiogram was done and showed patent ductus arteriosus and ventricular septal defect, abdominal ultrasound showed fused renal ectopia or double collecting system.

Chromosomal analysis and tandem mass spectrometry screening was done for the baby. Later on chromosomal analysis confirmed the diagnosis of trisomy 18 (Edward syndrome). CT scan was requested and showed cystic dilatation of the left nasolacrimal duct causing obstruction of the anterior part of the left sided nasal cavity with nasal septum deviation toward the right side which causes an obstruction of the right sided nasal cavity (Figure 2). MRI was done and showed cystic nature of the left nasolacrimal duct and the subsequent obstruction of both nasal cavities (Figure 4).

The baby was taken to operation room by pediatric surgeon for colostomy, and at same setting he underwent diagnostic rigid nasal endoscopy which showed a cystic mass in the left nostril coming from undersurface of the left inferior turbinate blocking the left nostril with anterior septal deviation blocking the right nostril, No evidence of choanal atresia or pyriform aperture stenosis was found (Figure 3). The baby was taken again to the operation room and he underwent endoscopic surgical marsupialization of the cyst with lacrimal duct probing and rinsing.

Histopathology report came as fibrous cyst wall lined partly by ciliated columnar epithelium and partly by squamous epithelium consistent with dacryocystocele wall. On 2 nd day after operation the baby was extubated and symptoms of respiratory distress disappeared. The baby was followed for two months after extubation with no documented events of upper respiratory distress then the baby passed away at age of 73 days.

\section{Discussion}

In the sixth fetal month, the nasolacrimal duct develops by canalization of the embryonic epithelial cord resulting of invagination of the ectodermal tissue localized between the maxillary process and the lateral aspect of the nasal process. The development of the draining lacrimal ducts is completed with the opening of the lacrimal points at the lid margins (The Rosen-Müller valve) and with the opening of the nasolacrimal duct into nose (valve of Hasner) [8]. Rarely an obstruction in the upper as well as lower part of the nasolacrimal drainage system may lead to cystic extension of the lacrimal duct that can already be enlarged prenatally with amnion fluid [9]. Symptoms can manifest at birth or in the first few weeks of life.

The true prevalence of intranasal cysts associated with dacryocystocele is unknown. A literature search revealed 82 out of

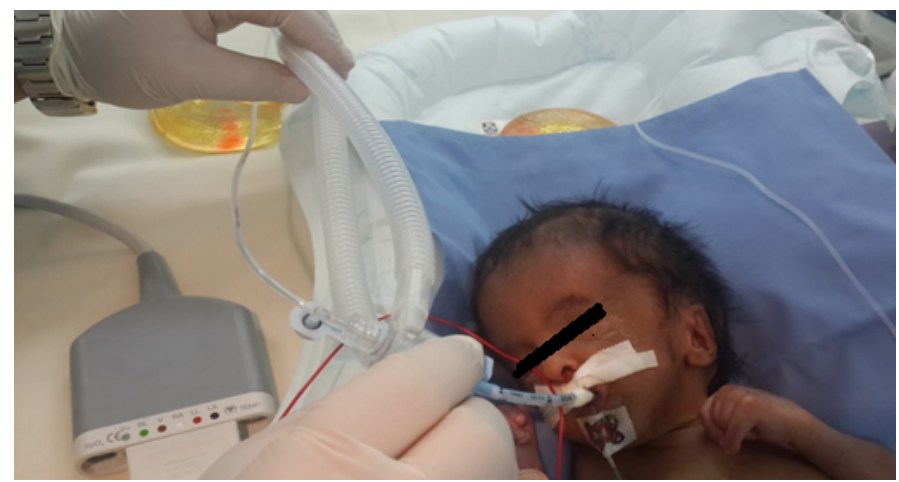

Figure 1. Clenched hand and overlapping fingers: index finger overlaps third finger and fifth finger overlaps fourth finger, characteristically seen in trisomy 18 .

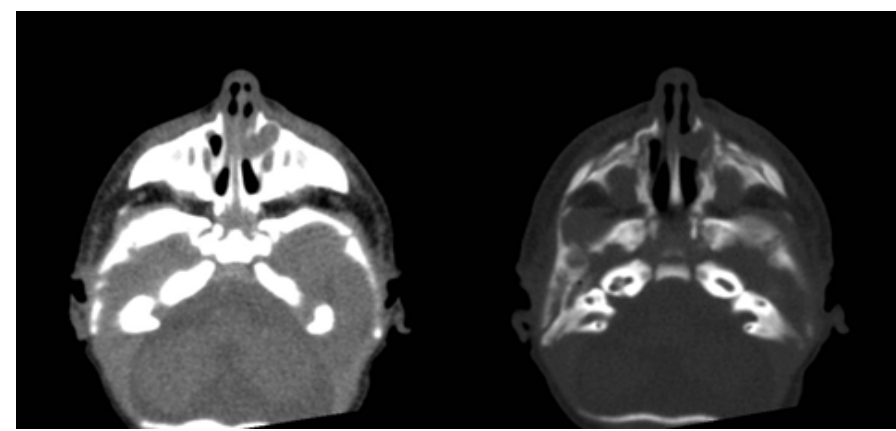

Figure 2. Axial section of noncontrast CT scan of head at the level of nasal cavity show cystic dilatation of the left nasolacrimal duct causing obstruction of the anterior part of the nasal cavity. There is associated nasal septum deviation toward the right side which causes obstruction of the right nasal cavity.

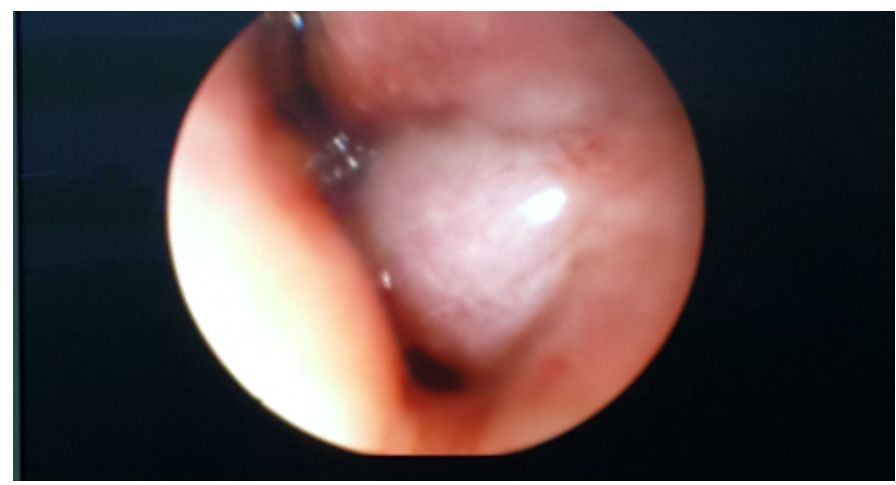

Figure 3. Endoscopic view of dacryocystocele arising from the left inferior meatus.

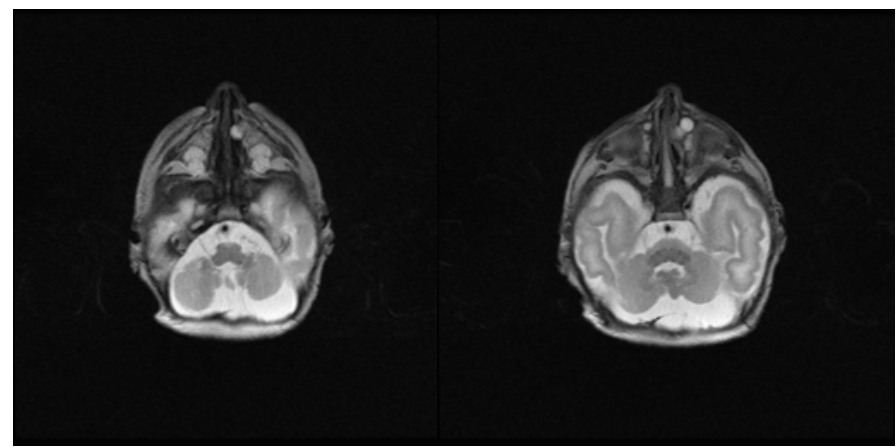

Figure 4. MRI T2 weighted images axial sections of the same patient confirmed the cystic nature of the left nasolacrimal duct and the subsequent obstruction of both nasal cavities.

186 reported cases of intranasal cysts associated with dacryocystoceles and prevalence rates ranged between $11 \%$ and $100 \%$. The summary of reported cases are illustrated in Table 1 [10]. About three -quarters of all cases were female infants [11]. Only rarely, a relation to syndromes was reported [12]. No reported cases of association between Edward syndrome and dacryocystocele were found upon review of the literature and we think that is a case of coincidence.

The external swelling at the medial canthal angle was described in most of the reports in the literature as the main clinical appearance that is often accompanied by an additional cystic part endonasaly. But, in the present case, the dacryocystocele occurred only endonasally. Differential diagnosis of intranasal masses includes a variety of congenital malformations, inflammatory conditions and tumors (Table 1) [13].

Diagnostic studies such as computed tomography (CT scan) or magnetic resonance imaging (MRI) are recommended to determine 
Table 1. Summary of Cases

Congenital

- Choanal atresia

- Meningo-encephalocele

- Dermoid cyst

- Thornwood's cyst

- Haemangioma

- Pyriform aperture stenosis

- Endonasal dacryocystocele

Neoplastic processes

- Glioma

- Craniopharyngioma

Trauma

Inflammatory

- Dacryocystitis

- Syphilis

- Edema

the extent of dacryocystocele and to exclude other differential diagnosis. MRI has an advantage for description of the soft parts as well as possible relation with the central nervous system before taking a biopsy or doing any surgical interventions. Furthermore, it allows a better differentiation between cystic lesions and solid tumors.

Simple dacryocystocele can be managed conservatively with massage and warm compresses. Intranasal lacrimal duct cysts are best managed surgically [14]. Three surgical options have been reported: Blind probing of the nasolacrimal duct [15], Nasal endoscopy and marsupialization of the intranasal cyst [16] or Combined endoscopic marsupialization and nasolacrimal duct probing [17,18]. Probing the nasolacrimal duct disrupts The Rosen-Müller valve and allows proximal decompression of the nasolacrimal apparatus. Endoscopic marsupialization decompresses the system distally, allowing drainage of retained mucopurulent secretions. Combined probing and marsupialization, as performed in our patient, re-establishes continuity of the nasolacrimal system and facilitates a return to normal and physiological function.

\section{Conclusion}

Unilateral dacryocystocele with an intranasal extension represents a rare congenital cause of neonatal respiratory distress. Acute airway stabilization may be necessary prior to investigation by anterior rhinoscopy, nasal endoscopy and either CT or MRI. Definitive management is surgical, including endoscopic marsupialization, lacrimal probing and irrigation of lacrimal duct to ensure patency of the nasolacrimal apparatus.

\section{Ethical approval}

All procedures performed in studies involving human participants were in accordance with the ethical standards of the institutional and/ or national research committee and with the 1964 Helsinki declaration and its later amendments or comparable ethical standards.

\section{References}

1. Teymoortash A, Hesse L, Werner JA, Lippert BM (2004) Bilateral congenital dacryocystocele as a cause of respiratory distress in newborn. Rhinology 42: 41-44. [Crossref]

2. Góralówna M, Tarantowicz W (1979) Imperforation of the nasolacrimal duct as a cause of nasal obstruction in the newborn. Rhinology 17: 173-175. [Crossref]

3. Edwards syndrome (John Hilton Edwards) WhoNamedlt.com. Retrieved 2008-07-24.

4. Health; Edwards syndrome (2011) BBC Archived from the original on December 2, 2011. Retrieved 2012-01- 04 .

5. Trisomy 18; MedlinePluse Medical Encyclopedia.Nlm.nih.gov.2011-12-14.Retrieved 2012- 01-04.

6. Trisomy 13 survival can exceed 1 year 1 OB/GYN News. Find articles. 2003-03-01. Retrieved 2012-01- 04

7. Chen MD (2008) Harold. "Introduction to Trisomy 18". EMedicine. Retrieved 2008 $07-24$.

8. Sevel D (1981) Development and congenital abnormalities of the nasolacrimal apparatus. J Pediatr Ophthalmol Strabismus 18: 13-9. [Crossref]

9. Harris GJ, DiClementi D (1982) Congenital dacryocystocele. Arch Ophthalmology 100: $1763-1765$.

10. Wong KM, Jachens AW, Bortz J, Moscatello A (2012) Bilateral congenital dacryocystoceles with intranasal mucoceles in the neonate. Open Journal of Pediatrics 2: $178-180$

11. Mansour AM, Cheng KP, Mumma JV, Stager DR, Harris GJ, et al. (1991) Congenital dacryocele. A collaborative review. Ophthalmology 98: 1744-1751. [Crossref]

12. Sharony R, Raz J, Aviram R, Cohen I, Beyth Y, et al. (1999) Prenatal diagnosis of dacryocystocele: a possible marker for syndromes. Ultrasound Obstet Gynecol 14:7173. [Crossref]

13. Leonard DS, O'Keefe M, Rowley H, Hughes JP (2008) Neonatal respiratory distress secondary to bilateral intranasal dacryocystoceles. Int J Pediatr Otorhinolaryngol 72: 1873-7. [Crossref]

14. Jin HR, Shin SO (1999) Endoscopic marsupialization of bilateral lacrimal sac mucoceles with nasolacrimal duct cyst. Auris Nasus Larynx 26: 441-445. [Crossref]

15. Yee SW, Seibert RW, Bower CM, Glasier CM (1994) Congenital nasolacrimal duct mucocele: a cause of respiratory distress. Int J Pediatr Otorhinolaryngol 29: 151-158. [Crossref]

16. Roy D, Guevara N, Santini J, Castillo L (2002) Endoscopic marsupialization of congenital nasolacrimal duct cyst with dacryocele. Clin Otolaryngol Allied Sci 27: 167-170. [Crossref]

17. Grin TR, Mertz JS, Stass-Isern M (1991) Congenital nasolacrimal duct cysts in dacryocystocele. Ophthalmology 98: 1238-1242. [Crossref]

18. Lueder GT (1995) Neonatal dacryocystitis associated with nasolacrimal duct cysts. $J$ Pediatr Ophthalmol Strabismus 32: 102-106. [Crossref]

Copyright: (C2017 Kurdi AA. This is an open-access article distributed under the terms of the Creative Commons Attribution License, which permits unrestricted use, distribution, and reproduction in any medium, provided the original author and source are credited. 